\title{
Mechanochemical Conversion of 11-Azaartemisinin into Pharmaceutical Cocrystals with Improved Solubility
}

Madiha Nisar $^{1}$, Richard K. Haynes ${ }^{1,2}$, Herman H-Y. Sung ${ }^{1}$ and lan D. Williams ${ }^{1}$

1. Department of Chemistry, Hong Kong University of Science and Technology, Clear Water Bay, Kowloon, Hong Kong, China. 2. Centre of Excellence for Drug Research and Development, North-West University, Potchefstroom, South Africa.

E-mail: mnisar@connect.ust.hk

11-Azaartemisinin (Azaart), an analogue of Artemisinin, is known to have noticeable antimalarial activity against Plasmodium falciparum and maybe considered as an active pharmaceutical indredient (API). ${ }^{[1][2]}$ Poor pharmacokinetic properties of Artemisinin and its analogues make them less attractive as a drug. Mechanochemical grinding of API can result into pharmaceutical cocrystals with altered physicochemical properties. $^{[3]}$ Liquid assisted grinding (LAG) was performed for screening of Azaart with a list of pharmaceutical coformers. Powder XRD data indicated eight successful cocrystallizations of Azaart could be found in an initial screen. The cocrystal of Azaart with rac-Mefloquine $\mathrm{HCl}$ (meflo) and L-(-)-Malic acid (Lmal) has now been prepared by solution method for single crystal XRD analysis. The crystal structure of (Azaart).(meflo) cocrystal is triclinic $\mathrm{P} 1$ and each unit cell is a complex asymmetric unit possessing two Azaart molecules and one unit formula of rac-Mefloquine. $\mathrm{HCl}$. (Azaart) $2 .(\mathrm{L}-\mathrm{mal})$ cocrystal has a 2:1 phase and the L-Malic acid is 50:50 with 2-fold disorder of $\mathrm{OH}$. The crystal structure is Orthorhombic with P2 $2{ }_{1} 2$ space group. The amide functionalites of both Azaart serve as hydrogen bond donors and acceptors in the cocrystals. The thermal stability and solubility of the new cocrystals are greatly enhanced compared to the parent Azaart itself. The single crystal growth of these other phases is in progress and details will be presented as available.

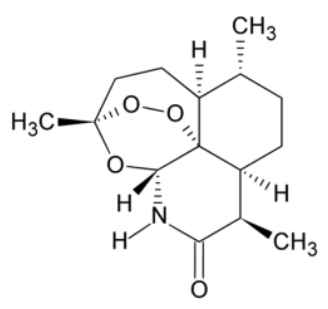

11-Azaartemisinin<smiles>OC(c1cc(C(F)(F)F)nc2c(C(F)(F)F)cccc12)C1CCCCN1</smiles>

Mefloquine hydrochloride

\section{References}

1. Torok D. S., Ziffer H., Meshnick S. R., Pan X.-Q. and Ager A., "Synthesis and antimalarial activities of N-substututed 11Azaartemisinins", Journal of Medicinal Chemistry, Vol. 38, (1995), pp 5045 -5050.

2. Haynes, R. K., Wong, H. N., Lee, K. W., Lung, C. M., Shek, L. Y., Williams, I. D. and Wong, V. K., "Preparation of N-Sulfonyl-and NCarbonyl-11-Azaartemisinins with Greatly Enhanced Thermal Stabilities: in vitro Antimalarial Activities", ChemMedChem, Vol. 2, No. 10, (2007) pp 1464-1479.

3. Remenar, J. F., Morissette, S. L., Peterson, M. L., Moulton, B., MacPhee, J. M., Guzman, H. R. and Almarsson, Ö., (Crystal engineering of novel cocrystals of a triazole drug with 1,4-dicarboxylic acids", Journal of. American Chemical Society, Vol. 125, (2003), 8456-8457. 